OPEN ACCESS

Edited by:

Giancarlo Condello,

University of Taipei, Taiwan

Reviewed by:

Verena Klusmann,

University of Konstanz, Germany

Pengcheng Wang,

Renmin University of China, China

${ }^{*}$ Correspondence:

Cheng Chen

cheng.chen2@kit.edu

Specialty section:

This article was submitted to

Movement Science and Sport

Psychology,

a section of the journal

Frontiers in Psychology

Received: 13 November 2020

Accepted: 14 May 2021

Published: 10 June 2021

Citation:

Chen C, Finne E, Kopp A and Jekauc D (2021) What Intervention Techniques Are Effective in Changing

Positive Affective Variables and

Physical Activity? A Systematic

Review and Meta-Analysis.

Front. Psychol. 12:628993.

doi: 10.3389/fpsyg.2021.628993

\section{What Intervention Techniques Are Effective in Changing Positive Affective Variables and Physical Activity? A Systematic Review and Meta-Analysis}

\author{
Cheng Chen ${ }^{1 *}$, Emily Finne ${ }^{2}$, Alexandra Kopp ${ }^{3}$ and Darko Jekauc ${ }^{1}$ \\ ${ }^{1}$ Institute of Sports and Sports Science, Karlsruhe Institute of Technology (KIT), Karlsruhe, Germany, ${ }^{2}$ Department \\ Prevention and Health Promotion, School of Public Health, Bielefeld University, Bielefeld, Germany, ${ }^{3}$ Department of Sport \\ Science, Institute of Sport Sciences, Humboldt University of Berlin, Berlin, Germany
}

A recent meta-analysis has demonstrated that positive affective variables (PAVs) partially mediate physical activity (PA) interventions. However, the effectiveness of each intervention technique on PAVs and PA is still unknown. Thus, this meta-analytic review included two primary objectives: (1) to summarize intervention effects on PA and PAVs; (2) to examine each behavior change technique's effectiveness in modifying PAVs and PA. Following PRISMA protocols, we had searched five electronic databases by April 1, 2020. The random-effect model in the Comprehensive Meta-Analysis Version 3 was adopted to perform these meta-analytic analyses. The search identified 1,742 articles, and 37 studies (49 datasets) met our inclusion criteria. Finally, inferential statistics yielded that: the utilization of "teach to use prompts/cues," "facilitate social comparison," and "provide information on consequences of behavior in general" had positive effects on PA or PAVs outcomes; the utilization of "barrier identification/problem solving" and "plan social support/social change" negatively affected on PA or PAVs outcomes. However, there was considerable heterogeneity in the findings. Nonetheless, this paper has considerable implications for guiding future comparative intervention studies to achieve more reliable outcomes.

Keywords: intervention, technique, positive affective variable, physical activity, moderator

\section{INTRODUCTION}

Regular physical activity (PA) is highly beneficial for the prevention of premature mortality (Ekelund et al., 2016) and for physical and mental health (Penedo and Dahn, 2005). However, only a minority of modern adults report that their PA participation levels align with most public health guidelines. Besides, a further 50\% of exercisers drop out within the first 6 months after initial participation (Finne et al., 2019). Exploring ways to promote and maintain PA is necessary because the benefits are not sustainable without consistent and regular attendance (Annesi, 2003). 


\section{The Unfavorable Commonality in Mainstream Physical Activity Change Theories}

Current mainstream theoretical approaches used for PA interventions include social cognitive theory (SCT; Bandura, 1998), the theory of planned behavior (TPB; Ajzen, 1991), the trans-theoretical model (TPB; Prochaska and Velicer, 1997), and self-determination theory (SDT; Deci et al., 1994). According to SCT, PA variations are regulated by reciprocal determinations among personal cognitive factors (e.g., self-efficacy, outcome expectations, knowledge), the physical and social environment (e.g., observational learning, normative beliefs, social support, opportunities, and barriers), and behavioral factors (e.g., behavioral skills, intentions, reinforcement) (Bandura, 2004). TPB comprises three core components, namely, attitude, subjective norms, and perceived behavioral control, which together shape individuals' PA intentions and behavior (Ajzen, 1991). The TTM has concentrated on stages of change, processes of change, levels of change, self-efficacy, and temptation (Prochaska and Velicer, 1997). And SDT emphasizes the role of autonomy, competence, and relatedness for PA interventions (Deci and Ryan, 2008). All of these theories share a core attribute that stems from cognitivism. In detail (1) they all emphasize the primacy of imagined end states (behaviors or goals) (Brand and Ekkekakis, 2018) in PA change, and (2) affective constructs are either entirely omitted or subordinated to cognitive devices, while the idea that affective constructs can serve as motivational forces outside of cognitivism (e.g., momentary emotions associated with physical activity situations; Ekkekakis, 2017) is ignored. Consistent with these theories, PA interventions have focused primarily on techniques that provide education about PA's benefits, build perceived ability, and selfregulation to perform PA (Conn et al., 2011; Chase, 2015; Rhodes et al., 2019). However, even as the framework predicting the highest amount of PA variance, the social cognitive theory can only explain, on average, $20 \%$ of the variation in PA maintenance (Jekauc et al., 2015). Rhodes et al. (2009a) integrated 34 PA intervention studies, and found that $85 \%$ of the findings showed that affective expectations were notable predictors of PA behavior $(r=0.43 ; 95 \%$ CI $=0.36-0.46)$, whereas only $35 \%$ of the findings showed that instrumental expectations were significant predictors of PA behavior $(r=0.25$; 95\% CI $=0.21-0.29)$. Hence, perhaps the failure to separate the affective and instrumental reflections or expectations of the intervention on PA hinders the exploration process of PA promotion (McEwan et al., 2016; Jekauc and Brand, 2017). Therefore, a more refined meta-analysis dedicated to affective variables and PA is inevitable (Jekauc et al., 2015).

\section{Definitions of Positive Affective Variables}

In general, "affect is the experiential state of feeling and is a collective term describing feeling states such as emotion and mood" (Gellman and Turner, 2013). Affective states may vary in several aspects, such as their duration, intensity, specificity, pleasantness, and degree of arousal, and they have essential roles in regulating cognition, behavior, and social interaction.
As a superordinate category, emotions and moods belong to affect. Emotions and moods differ mainly in (1) their duration: emotions are rather brief and intense experiences, and moods last somewhat longer than emotions, and (2) whether they are directed to a specific cause: emotions are reactions to specific external stimuli (i.e., objects or events) and may arise relatively automatically or after a cognitive assessment of the stimulus; moods are more diffuse in nature (Gellman and Turner, 2013). Furthermore, the concept of attitude is considered to represent relatively enduring beliefs and preferences for a particular organism and is primarily composed of cognitive, affective, and motivational components (Breckler, 1984). Contrary to the caution of theorists, namely that these concepts should be distinguished, affect, emotion, feeling, mood and affective attitude (Ostrom, 1969) are often used liberally in empirical researches (Batson et al., 1992). Thus, this paper integrated them into a generalized term as affective variables. Besides, some other theorists have noted that organizing affective variables by dimension may be more meaningful than considering them by category (Cacioppo and Gardner, 1999; Watson et al., 1999; Shiota and Kalat, 2012). Thus, we generalized nonnegative affect, emotion, feeling, mood, and affective attitude and use the term "positive affective variables (PAVs)" to refer to them.

\section{Approach-Avoidance Distinction of Affective Variables and Motivation in Physical Activity}

According to existing research, the approach-avoidance distinction is applicable in affective variables (positive and negative affective dispositions) (Watson et al., 1999). The neurological underpinnings have also given evidence of this linkability between motivation and emotion through affective neuroscience (Davidson, 2003). As Larsen et al. (2008) stated, "motivation and valence tend to be correlated, such that positive emotions are associated with approach and negative emotions with avoidance." Consistently, it could also be shown that positive emotions (e.g., enjoyment) during PA and intrinsic motivation for PA possibly share common determinants (Wienke and Jekauc, 2016). Furthermore, several other theoretical and empirical studies also have shown that PAVs are essential determinants of PA behavior or outcomes (Rhodes et al., 2009b). Following the upward spiral theory of lifestyle change, motivation is significantly associated with positive affects experienced during healthy behaviors, and motivational salience subconsciously guides attention to these behaviors and decisions to repeat them (van Cappellen et al., 2018). Further, a recent meta-analysis emphasized that the PAV emerges as a significant mediator between intervention and PA outcomes (Chen et al., 2020). Based on these neuroscientific, theoretical, and empirical fundamentals, enhancing PAVs is more likely to facilitate physical activity than activities that rely primarily on extrinsic motivation, such as those expected to improve health and well-being (Nielsen et al., 2014). 


\section{Empirical Studies on Positive Affective Variables and Physical Activity}

In recent years, there has been an upsurge of enthusiasm to consider the role of PAVs in PA prescribing more (e.g., Ekkekakis et al., 2013, 2020), but our knowledge of how to change PAVs and subsequent PA remains deficient. So far, Rhodes and his colleagues have conducted three reviews (Rhodes et al., 2009a, 2019; Rhodes and Kates, 2015), which summarized the relationship between affective response/affective judgment (i.e., thoughts about the overall pleasure/displeasure, enjoyment, and feeling states expected from enacting a behavior) and PA. Initially, through 82 correlational studies and 20 eligible experimental studies, Rhodes et al. (2009a) demonstrated a medium-effect size relationship between affective judgment and PA. A significant positive correlation between affective judgments and PA was reported in 83 out of 85 correlational samples, with a pooled $\mathrm{r}$ of $0.42(95 \% \mathrm{CI}=0.37-0.46)$. A further meta-analytic synthesis was reported in 2015. It stated that positive changes in primary affective responses during moderateintensity exercise were associated with future PA intention (Rhodes and Kates, 2015). A recent review explored interventions to manipulate adults' (of healthy and unhealthy populations) affective judgments and subsequent PA, but no technique was considered adequate (Rhodes et al., 2019). We speculate that two main reasons influenced these results. First, it is well-known that many diseases (e.g., Alzheimer's disease) can change emotional regulation (Bucks and Radford, 2004), so it is necessary to distinguish between healthy and unhealthy populations. Second, we presumed that Rhodes et al. (2019) did not distinguish between intrinsic motivation and affect in the literature inclusion (Silva et al., 2010a,b; Moustaka et al., 2012; Kinnafick et al., 2016; Shah et al., 2016) leading to these outcomes. According to Weinberg and Gould (2014, pp. 139), intrinsic motivation includes knowledge, accomplishment, and stimulation, while affect is merely a part of intrinsic motivation (stimulation). Besides, we desired to exclude negative affective variables from this study (Egloff, 1998; Reich et al., 2001). The reasons were: (1) Reich et al. (2001) conducted two experiments based on the two-factor model and the bipolar model, which showed that the cognitively more complex participants reported the mutual independence of positive and negative affect, while those with simpler cognitions reported the polarity of positive and negative affect, which meant that positive and negative affects could be differentiated for exploration; (2) as we described in the previous paragraph, the approach-avoidance distinction was also applicable in the affective variables; (3) Chen et al. (2020) distinguished between positive and negative affective variables and demonstrated the significant mediating role of PAVs in the PA intervention. Overall, we would like to implement a more nuanced meta-analysis to understand how PAVs and PA can be manipulated in healthy populations.

Considering the aforesaid, this paper included two primary objectives. First, to summarize intervention effects on PA and PAVs; second, examine each behavior change technique's effectiveness in modifying PAVs and PA and exploring potential demographic and methodological moderators. That is, we investigated (1) which methodological factors moderated the outcomes of PAVs and PA (e.g., study design, theory framework, intervention duration, measurement, number of intervention techniques used); (2) which demographic characteristics moderated the results of PAVs and PA interventions (e.g., age, gender, population setting, PA level at baseline); (3) which behavior change techniques (BCTs) were the most effective for PAVs and PA interventions.

\section{METHODS}

\section{Search Strategy and Inclusion Criteria}

The literature search was conducted according to the PRISMA standard protocol (Moher et al., 2009) (see Figure 1). A structured electronic search strategy was used to retrieve studies published by April 1, 2020. The databases searched included Web of Science, PubMed, PsycINFO, PsycArticle, and Psychology and Behavioral Sciences Collection. The search terms were: (1) Intervention OR Trial OR Experiment; (2) Physical Activity OR Exercise; (3) Enjoy* OR Affect* OR Emotion* OR Mood* OR Feeling; (4) Mechanism* OR Mediat* OR Predict* OR Process* OR "Structural equation modeling" OR Caus* OR Path* OR Correlat* OR Relationship OR Associat*; (5) NOT (Patient* OR Cancer OR Clinical OR Disease* OR Illness OR Depression OR Rat OR Mouse OR Protocol OR Cell OR Bone* OR Blood OR Rehabilitation OR Disorder* Injur* OR HIV OR Carbohydrate OR Athlete* OR Player* OR Runner* OR Review OR Comment OR Therapy); (6) 1 AND 2 AND 3 AND 4 AND 5. Besides, more than 98 percent of the search results were in English, and very few studies were published in other languages. Hence, we only included studies published in English for the accuracy of data extraction.

The first author completed the search, and the eligibility of each study was determined by the Cochrane handbook for systematic reviews of intervention studies (Higgins et al., 2019b). Studies in which the first author was unsure whether to be included were discussed and determined with the last author. A study was eligible for our meta-analysis if it met the following criteria: (1) experimental studies assessing PAV as a dependent variable; (2) PAV was a target of the intervention; (3) studies whose goal was to increase lifestyle or recreational PA, not for competitive sports (Caspersen et al., 1985; Vanhees et al., 2005); (4) sufficient data to calculate the effect sizes (Hedges' g) of PAVs and PA; (5) participants were healthy individuals (not a clinically defined population and not pregnant). Furthermore, we intentionally chose a minimum duration of PA of $10 \mathrm{~min}$, given that $10 \mathrm{~min}$ is the recommended minimum duration of exercise to elicit health benefits (Edwards and Loprinzi, 2019).

\section{Data Extraction and Data Analysis}

First, the risk of bias assessment was administered using the STROBE standard tool (Elm et al., 2007). The tool includes questions in a "yes" (1) or "no" (0) format (e.g., did the study report the sources and details of PA assessment; did the instruments have acceptable reliability for the specific age group?). Study qualities were assessed by the first and last authors 


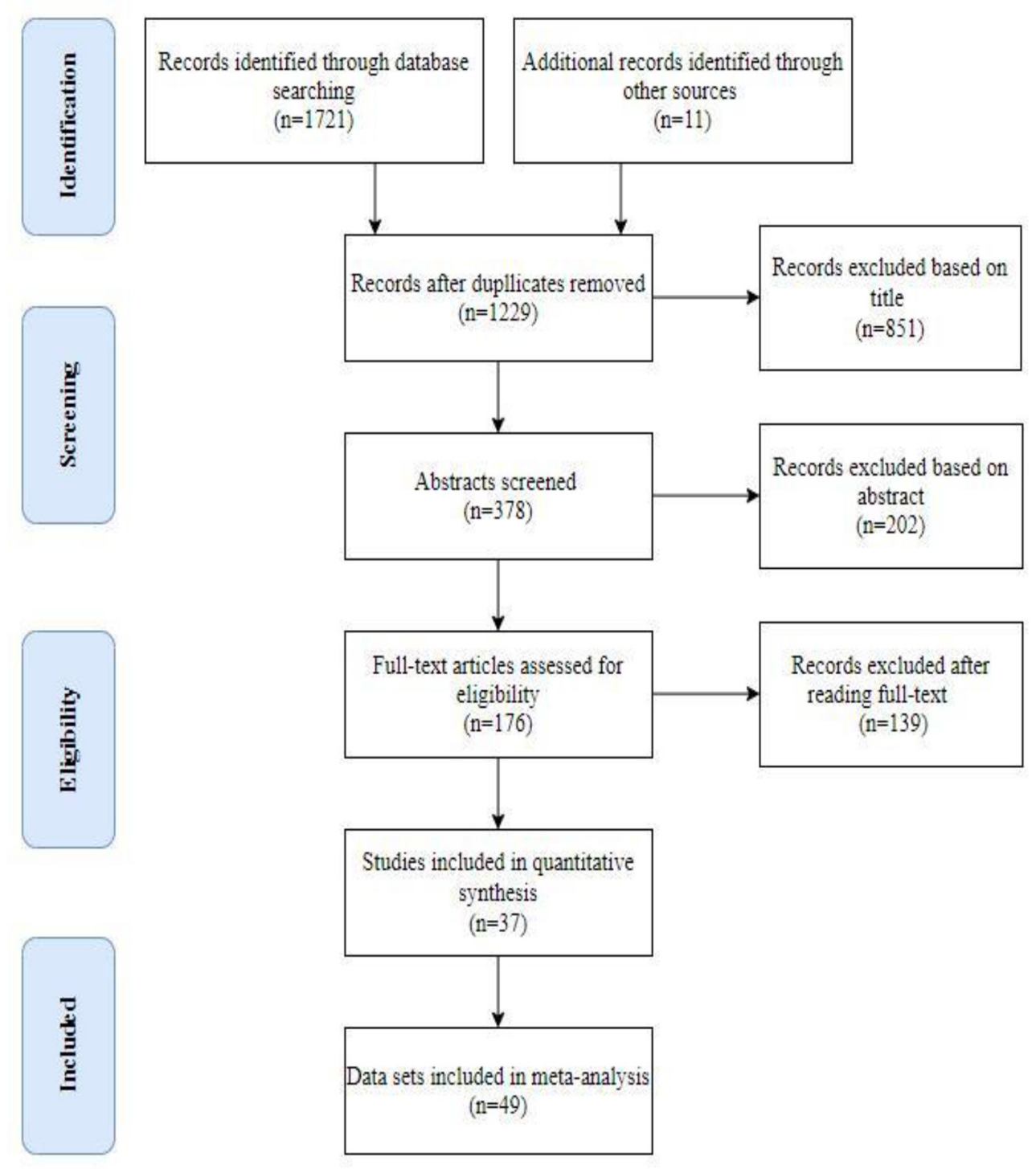

FIGURE 1 | PRISMA flow diagram for articles identified, screened eligible, and included in this paper.

separately, and any differences were resolved through discussion. The studies' quality was then graded as low (scores $0-2$ ), medium (scores 3-4), or high (scores 5-6).

Next, with the supervision and guidance of the last author, the first author completed the extraction of the following data: BCTs; the PAVs' constructs, dimensions, and measurements; PA assessment methods, variables, measures; methodological data (e.g., study design, theory framework, intervention duration, measure employed, number of intervention methods used, primary intervention targeted, PA focus); demographic data (e.g., age, gender, population setting, PA level at baseline). Data for BCTs were extracted based on the 40 -item taxonomy by Michie et al. (2011). Coyne et al. (2010) pointed out that several small sample studies can be included in a meta-analysis, but if a metaanalysis includes many small sample studies, it may result in a large bias in its effect size. For this reason, we classified each trial according to whether its sample size was $>35$ (Kraemer et al., 1998; Coyne et al., 2010) and calculated the sample size as a moderator variable in the calculation.

Finally, we adopted the statistical procedure utilized by Ashford et al. (2010) and Williams and French (2011). The random-effect model in the Comprehensive Meta-Analysis Version 3 (Borenstein et al., 2014) was employed in the calculation. Based on the raw data, we employed Hedges' $g$ to estimate effect sizes (i.e., the adjusted standardized mean difference for both PAVs data and PA data between post-test means in intervention and control group where possible, or pre and post-test means of the intervention group) (Durlak, 2009). With multiple measurement time points, we chose the first measurement taken at the end of the intervention (Higgins 
et al., 2019b) because those results could maximally be influenced by different interventions and less influenced by other factors relative to the follow-up measurements. To overcome the potential unit-of-analysis error due to the inclusion of multiarm studies, several approaches have been proposed by Higgins et al. (2019a). Specifically, when exploring the moderating effects of each methodological and demographic variable, we combined all intervention groups within a study to create a single pairwise comparison (Higgins and Li, 2019). We then computed the summary effect for this intervention group vs. the control group. However, when performing moderator analyses for BCTs, we included each pair-wise comparison separately, but shared control groups were divided into several smaller groups for the different comparisons to avoid "double counting." Moderator analyses were limited to categories with at least three studies. The findings' heterogeneity was examined using the Q-statistic (Higgins et al., 2003; Hedges and Pigott, 2004); a 5\% cut-off was used for significance. The Q coefficient's significance represents the heterogeneity of the dataset beyond what would be expected from sampling error alone, suggesting that additional systematic factors contribute to the variance. Therefore, we performed moderator analyses to explore the causes of heterogeneity by comparing the mean variability of effect size estimates for two groups of studies characterized by the presence or absence of a specific study characteristic (e.g., a specific BCT) (Ashford et al., 2010). Finally, we explored publication bias using Egger's regression intercept (i.e., a statistical test result for funnel plot asymmetry), and a 5\% cut-off was used for significance.

\section{RESULTS}

\section{Study Flow and Characteristics}

The search identified 1,732 articles, of which 1,352 were duplicates or could be excluded based on the titles. Of the remaining 389 articles, there were 183 articles for full-text review, of which 11 were identified by cross-referencing (see Figure 1). Finally, 37 studies met our inclusion criteria (see Appendix 8), of which ten studies contained two or three subgroups (Focht et al., 2007; Rose and Parfitt, 2007; Schneider and Cooper, 2011; Fitzsimons et al., 2012; Kraft et al., 2015; Wang et al., 2015; Niedermeier et al., 2017; Noradechanunt et al., 2017; Miragall et al., 2018; Gråstén and Yli-Piipari, 2019). Due to the nature of the data to be analyzed, we included each pair-wise comparison separately when investigating BCTs' moderating effects on PAVs and PA and therefore included a total of 49 data sets. In case of multiple comparisons to the same reference group, we split the control group as described above. Meanwhile, the quality of each study is presented in Appendix 1. Of the 37 studies, six were rated as high quality, 17 were rated as low quality, and the remaining 20 studies were rated as moderate quality.

Furthermore, the general characteristics of the 37 studies are presented in Appendix 2. Then, Table 2 presents the overall study characteristics of the 37 studies. Concerning the age of the participants, four age intervals were designed to classify the mean age of each study: under 18 years $(n=15), 18-35$ years $(n=$ $13)$, 36-60 years $(n=7)$, and over 60 years $(n=2)$. In terms of gender distribution, only one group identified its gender as male, 11 studies defined its gender as female, and the remaining 25 studies were mixed gender. For baseline PA, we marked out four classifications as "not meeting PA guidelines at baseline" $(n=17)$, "meeting PA guideline at baseline" $(n=3)$, "mixed" $(n=9)$, and "unreported" $(n=8) .33$ of the 37 studies stated their theoretical underpinnings, while the other four did not. In addition, 16 interventions were implemented based on multiple theoretical frameworks, and 17 interventions were based on a single theoretical framework (TTM $n=3, \operatorname{SCT} n=3$, TPB $n=$ 3 , SDT $n=3$, the dual-mode model $n=1$, challenge point theory $n=1$, tactical games model $n=1$, affective reflective theory $n=$ 1 , the health promotion model $n=1$ ). The intervention duration of the included individual groups ranged from $<3 \mathrm{~h}-4$ years, but the majority was between 2 and 6 months $(n=12)$. Only 13 of the 37 studies randomized their subjects. Furthermore, over 55 percent of the interventions were performed in schools, colleges, and university laboratories.

\section{Contents of BCTs}

The intervention techniques employed by each intervention group are summarized in detail in Appendix 5. According to Michie et al. (2011), the 49 independent intervention groups used 2-17 intervention techniques, of which seven interventions employed no more than three intervention techniques, 23 interventions employed 4-10 intervention techniques, and 20 studies employed more than 10 intervention techniques. Further, Table 1 presents the frequency of use of each intervention technique across all included studies. The most frequently used intervention techniques were (1) provide instruction on how to perform the behavior $(83.67 \%)$, (2) provide instruction on when and where to perform the behavior (81.63\%); (3) action planning (57.14\%), and model/demonstrate the behavior $(57.14 \%)$. Six intervention techniques were not employed by any of the included studies: (1) shaping; (2) prompt generalization of a target behavior; (3) prompt identification as a role model/position advocate; (4) prompt anticipated regret; (5) fear arousal; (6) stimulate anticipation of future rewards. Five other intervention techniques were rarely used: (1) provide information on consequences of behavior to individual (4.08\%); (2) prompting focus on past success (4.08\%); (3) agree behavioral contract (4.08\%); (4) provide rewards contingent on effort or progress toward behavior $(2.04 \%)$; (5) provide rewards contingent on successful behavior (2.04\%).

\section{Characteristics of PAVs}

Appendix 3, Table 2 presents the constructs, dimensions, and measurements of each study's PAVs. First, PAVs could be categorized into two broad constructs of affects and emotional states (Shouse, 2005), with several studies measuring both of them. The dimensions of affect included "affective valence" and "positive affect," and the measurement methods were "feeling scale (FS)" and "positive and negative scale (PANAS)." Emotional states were further categorized as "enjoyment," "pleasure," "exercise-induced feeling," "affective attitude," and "mood state." There were various dimensions and methods to measure emotional states, and the most frequently measured dimension 
TABLE 1 | Frequencies of intervention techniques that were used in the intervention groups in meta-analytic analyses.

\begin{tabular}{|c|c|c|c|}
\hline \multicolumn{2}{|c|}{ Techniques } & \multirow{2}{*}{$\begin{array}{c}\text { Number of intervention } \\
\text { groups (maximum 49) } \\
15\end{array}$} & \multirow{2}{*}{$\begin{array}{c}\begin{array}{c}\text { Percentages } \\
(\%)\end{array} \\
30.61\end{array}$} \\
\hline 1 & Provide information on consequences of behavior in general & & \\
\hline 2 & Provide information on consequences of behavior to individual & 2 & 4.08 \\
\hline 3 & Provide information about others' approval & 9 & 18.37 \\
\hline 4 & Provide normative information about others' behavior & 5 & 10.20 \\
\hline 5 & Goal setting (behavior) & 19 & 38.78 \\
\hline 6 & Goal setting (outcome) & 6 & 12.24 \\
\hline 7 & Action planning & 28 & 57.14 \\
\hline 8 & Barrier identification/problem solving & 18 & 36.73 \\
\hline 9 & Set graded tasks & 10 & 20.41 \\
\hline 10 & Prompt review of behavioral goals & 13 & 26.53 \\
\hline 11 & Prompt review of outcome goals & 3 & 6.12 \\
\hline 12 & Provide rewards contingent on effort or progress toward behavior & 1 & 2.04 \\
\hline 13 & Provide rewards contingent on successful behavior & 1 & 2.04 \\
\hline 14 & Shaping & 0 & 0 \\
\hline 15 & Prompt generalization of a target behavior & 0 & 0 \\
\hline 16 & Prompt self-monitoring of behavior & 24 & 48.98 \\
\hline 17 & Prompt self-monitoring of behavioral outcome & 4 & 8.16 \\
\hline 18 & Prompting focus on past success & 2 & 4.08 \\
\hline 19 & Provide feedback on performance & 20 & 40.82 \\
\hline 20 & Provide instruction on when and where to perform the behavior & 40 & 81.63 \\
\hline 21 & Provide instruction on how to perform the behavior & 41 & 83.67 \\
\hline 22 & Model/demonstrate the behavior & 28 & 57.14 \\
\hline 23 & Teach to use prompts/cues & 6 & 12.24 \\
\hline 24 & Environmental restructuring & 15 & 30.61 \\
\hline 25 & Agree behavioral contract & 2 & 4.08 \\
\hline 26 & Prompt practice & 7 & 14.29 \\
\hline 27 & Use of follow-up prompts & 3 & 6.12 \\
\hline 28 & Facilitate social comparison & 4 & 8.16 \\
\hline 29 & Plan social support/social change & 25 & 51.02 \\
\hline 30 & Prompt identification as a role model/position advocate & 0 & 0 \\
\hline 31 & Prompt anticipated regret & 0 & 0 \\
\hline 32 & Fear arousal & 0 & 0 \\
\hline 33 & Prompt self-talk & 4 & 8.16 \\
\hline 34 & Prompt use of imagery & 9 & 18.37 \\
\hline 35 & Relapse prevention/coping planning & 3 & 6.12 \\
\hline 36 & Stress management/ emotional training & 24 & 48.98 \\
\hline 37 & Motivational interviewing & 6 & 12.24 \\
\hline 38 & Time management & 4 & 8.16 \\
\hline 39 & General communication skills training & 5 & 10.20 \\
\hline 40 & Stimulate anticipation of future rewards & 0 & 0 \\
\hline
\end{tabular}

was "enjoyment." Still, there were also "remembered pleasure," "revitalization," "positive engagement," "vigor," "activation," and "excitement." Accordingly, there were various scales for measuring emotional states, for example, "the physical activity enjoyment scale (PACES)," "the PE enjoyment scale (PEES)," "visual analog scale (VAS) of enjoyment/remembered pleasure," "the interest/enjoyment subscale of intrinsic motivation inventory (IMI)," "single-item enjoyment scale (SES)," "exerciseinduced feeling inventory (EFI)," "semantic differential scale of affective attitude (SD)," "profile of mood states (POMS)" and "mood survey scale (MSS)."

\section{Characteristics of PA}

In general, there were two broad categories of PA measurements: objective and subjective. Appendix 4, Table 2 shows that objective and subjective measures were about equally divided. The primary four objective measurements were the recording list (equipment usage log/attendance list), pedometer, accelerometer, 
TABLE 2 | Overall study characteristics of 37 studies.

\begin{tabular}{ccc}
\hline Characteristics & $N$ of intervention & Percentages (\%) \\
groups (maximum & \\
37 ) &
\end{tabular}

Age
$<18$
$18-35$
$36-50$
$50-75$
Gender
Male
Female
Mixed
Sample size
$<35$ participants per condition
$\geq 35$ participants per condition
Intervention duration
$\leq 3 \mathrm{~h}$
$3 \mathrm{~h}-2$ months
$2-6$ months (including 2 months)
$>6$ months

Number of intervention methods used

1-3 methods used

4-10 methods used

4-11 methods used

\section{Setting}

School

University

Lab

Community

Other

The physical activity level at baseline

Not meeting guideline

Meeting guideline

Mixed

Unreported

Positive affective variables measure

Affect

Emotional state

Affect and emotional state

Positive affective variables_measurements

The physical activity enjoymen

scale

The positive and negative affect

schedule

Feeling scale

IMI

Semantic differential scales of

affective attitude

Affective attitude Likert scale

Profile of mood states

Single-item enjoyment scale

The PE enjoyment scale

VAS

\section{5}

13

7

2

1

11
TABLE 2 | Continued

\begin{tabular}{|c|c|c|}
\hline Characteristics & $\begin{array}{c}N \text { of intervention } \\
\text { groups (maximum } \\
37 \text { ) }\end{array}$ & Percentages (\%) \\
\hline Multiple & 8 & 21.62 \\
\hline \multicolumn{3}{|l|}{ Physical activity measure } \\
\hline $\begin{array}{l}\text { Moderate-vigorous physical activity } \\
\text { (objective) }\end{array}$ & 2 & 5.41 \\
\hline $\begin{array}{l}\text { Moderate-vigorous physical activity } \\
\text { (subjective) }\end{array}$ & 9 & 24.32 \\
\hline Steps & 4 & 10.81 \\
\hline Frequency & 6 & 16.22 \\
\hline Intensity & 6 & 16.22 \\
\hline Multiple & 10 & 27.03 \\
\hline \multicolumn{3}{|l|}{ Physical activity measurements } \\
\hline $\begin{array}{l}\text { Equipment usage log/attendance } \\
\text { list }\end{array}$ & 5 & 13.51 \\
\hline HR monitoring & 5 & 13.51 \\
\hline Pedometer & 4 & 10.81 \\
\hline Accelerometer & 3 & 8.11 \\
\hline $2 / 3 / 7$ day physical activity recall & 3 & 8.11 \\
\hline $\begin{array}{l}\text { International physical activity } \\
\text { questionnaire }\end{array}$ & 2 & 5.41 \\
\hline Leisure-time exercise questionnaire & 2 & 5.41 \\
\hline Other questionaires & 8 & 21.62 \\
\hline Multiple & 4 & 10.81 \\
\hline Not reported & 1 & 2.70 \\
\hline \multicolumn{3}{|l|}{ Theory } \\
\hline No framework explicitly mentioned & 4 & 10.81 \\
\hline Social cognitive theory & 3 & 8.11 \\
\hline The transtheoretical model & 3 & 8.11 \\
\hline Theory of planned behavior & 3 & 8.11 \\
\hline Self-determination theory & 3 & 8.11 \\
\hline Multiple & 16 & 43.24 \\
\hline Others & 5 & 13.51 \\
\hline \multicolumn{3}{|l|}{ Study design } \\
\hline Randomized controlled study & 13 & 35.14 \\
\hline Quasi-experimental study & 24 & 64.86 \\
\hline \multicolumn{3}{|l|}{ Study quality rating } \\
\hline Low (1-2) & 7 & 18.92 \\
\hline Medium (3-4) & 24 & 64.86 \\
\hline High (5-6) & 6 & 16.22 \\
\hline
\end{tabular}

IMI, the interest/enjoyment subscale of intrinsic motivation inventory; VAS, visual analog scale of enjoyment/ remembered pleasure.

and heart monitor. In contrast, subjective measures of PA were diverse. For example, 7-day physical activity recall (7DPAR), 3-day physical activity recall (3DPAR), the shortform of the international physical activity questionnaire (IPAQ), physical activity time-consuming questionnaire (PATCQ), the children's leisure activities study survey (CLASS), 6-point exercise frequency scale (EFS). The PA variables measured by the studies were also highly diverse, for example, moderate to vigorous physical activity (MVPA), leisure-time physical 
activity (LTPA), the metabolic equivalent of task (MET), exercise adherence, equipment usage, \%Max HR.

\section{Moderating Effect of Methodological and Demographics Variables on PAVs and PA}

Meta-analytic moderation results of the 37 studies can be found in Table 3. We first reported the moderating effects of demographic and methodological factors on PAVs. Experimental manipulations of PAVs had an overall effect size $g=0.28(95 \%$ $\mathrm{CI}=0.14-0.41$ ) on PAVs (see Appendix 6). The examination of publication bias for the 37 studies was significant [Egger's intercept $t=1.65$ (35), $p=0.02$ ] (see Figure 2), and in cases such as this with small samples and large heterogeneity, caution should be exercised (Carter et al., 2019). Using the $n=35$ criterion proposed by Coyne et al. (2010), small-sample bias was a significant moderator in the PAV $(Q=6.64 ; p=0.01)$ context, with larger effect size $(g=0.32,95 \% \mathrm{CI}=0.08-0.57)$ reported for small sample sizes. Age was also a significant moderator to the findings $(Q=12.73, p<0.05)$, mean age interval located between 36 and 50 years reported the largest effect size $(g=0.48,95 \%$ $\mathrm{CI}=0.12-0.84)$. There was also a significant moderating effect of gender on PAVs, with the largest effect size for mixed-gender studies $(g=0.30,95 \% \mathrm{CI}=0.12-0.48)$. Similarly, there was a significant moderating effect of intervention duration on PAVs, with the largest effect size for intervention duration between $2 \mathrm{~h}$ and 2 months $(g=0.69,95 \% \mathrm{CI}=0.07-1.31)$. The theory was also a significant moderator in PAVs intervention, with SDT having the largest effect size $(g=0.80,95 \% \mathrm{CI}=0.33-1.27)$. However, neither the intervention setting $(Q=5.83, p=0.21)$ nor the baseline level of PA $(Q=6.54, p=0.09)$ were significant moderators in our PAVs investigation.

Next we would report the moderating effects of demographic and methodological factors on PA. The overall effect size of interventions on PA was $g=0.30$ (95\% CI $=0.10-0.48$ ) (see Appendix 7). However, the Egger regression intercept for the PA data was not significant ( $t=1.84(35), p=0.07$ ) (see Figure 3). The results of meta-analytic moderation analyses showed that small sample bias was not a significant moderator of PA outcomes $(Q=0.01, p=0.91)$. Age was a significant moderator of PA outcomes $(Q=19.23, p<0.01)$, with a maximum effect size reported for the mean age between 18 and 35 years $(g=0.44,95 \%$ $\mathrm{CI}=-0.10$ to 0.97$)$. Gender was also a significant moderating variable $(Q=11.53, p<0.01)$, with the mixed gender sample reporting larger effect size $(g=0.46,95 \% \mathrm{CI}=0.23-0.70)$. In addition, theory was also a significant moderator of PA outcomes $(Q=14.80, p=0.02)$, with the lagest effect sizes of "others" $(g=$ $1.03,95 \% \mathrm{CI}=0.18-1.88)$.

\section{Moderating Effect of Contents Applied in the Intervention on PAVs and PA}

We performed 29 meta-analytic moderation analyses based on a refined taxonomy of intervention techniques (Michie et al., 2011; see Table 1). It was not sensible to perform moderating analyses for the remaining 11 techniques because fewer than three intervention groups utilized them. Refer to Appendix 5 for details of the intervention techniques used in each intervention group.
The presence of two intervention techniques increased the variations in PAVs. They were "teach to use prompts/cues" (present $g=0.73$; absent $g=0.26, p=0.02$ ) and "facilitate social comparison" (present $g=0.98$; absent $g=0.26, p$ $=0.01$ ). However, the application of two other intervention techniques could reduce the outcomes of PAVs. They were "barrier identification/problem solving" (present $g=0.09$; absent $g=0.45, p=0.01$ ) and "plan social support/social change" (present $g=0.19$, absent $g=0.45, p=0.04$ ). None of the other 25 techniques included in the moderator analysis differed significantly in their effect size estimates between the two study groups, irrelevant of whether they included a specified technique or not (see Table 4).

The presence of three intervention techniques increased the variations in PA. They were "provide information on consequences of behavior in general" (present $g=0.54$; absent $g=0.26, p=0.04$ ), "teach to use prompts/cues" (present $g=$ 1.33 ; absent $g=0.25, p<0.01$ ) and "facilitate social comparison" (present $g=0.97$; absent $g=0.3, p=0.02$ ). However, the application of another intervention technique could reduce the outcomes of PA. It was "barrier identification/problem solving" (present $g=0.19$; absent $g=0.46, p<0.05$ ). None of the other 25 techniques included in the moderator analysis differed significantly in their effect size estimates between the two study groups, irrelevant of whether they included a specified technique or not (see Table 4).

\section{DISCUSSION}

This paper intended to provide a nuanced summary of the characteristics of current research methodologies for PAVs and PA interventions, identify intervention techniques that have been used sparingly, and determine the most compelling theories and techniques in recent researches. Therefore, this investigation had two series of objectives. First, summarize experimental studies targeting PAVs in order to change PA and their characteristics (study characteristics, BCT characteristics, PAV characteristics, PA characteristics); second, investigate the moderating effects of methodology, demographics, and BCTs.

\section{The Characteristics of Demographics and Methodologies}

The retrieved studies suggest that $83.78 \%$ of the included studies were of moderate or low quality, only about a third were RCTs, and approximately half were small sample studies. Besides, the majority of the retrieved studies were set in schools or universities, and only one study setting was the worksite. Approximately $70 \%$ of the studies did not specify subject genders; nearly $30 \%$ of the interventions targeted females only, with only one study exclusively targeting male subjects. Approximately $45 \%$ of the studies did not report on the subjects' PA level at baseline ("not meeting guideline" or "meeting guideline"), and the role of PAVs for different initial exercise conditions remained to be explored. Besides, PAVs were measured in various formats and dimensions, but no studies explained the differences and commonalities between those different formats and dimensions. 
TABLE 3 | Demography and methodology effects of experimental effects on PAVs and PA.

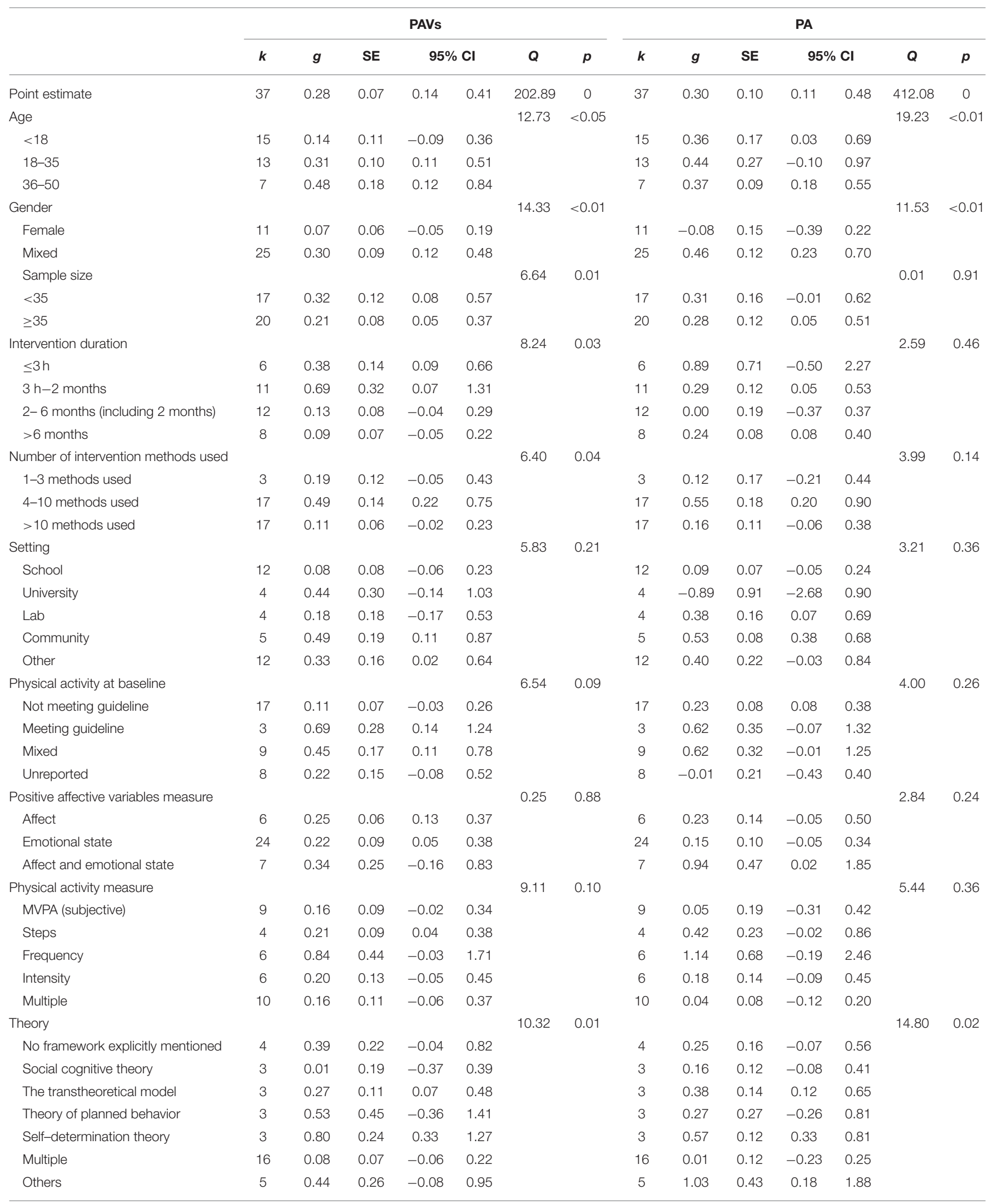




\begin{tabular}{|c|c|c|c|c|c|c|c|c|c|c|c|c|c|c|}
\hline & $k$ & \multicolumn{6}{|c|}{ PAVs } & \multicolumn{7}{|c|}{ PA } \\
\hline Study design & & & & & & 0.58 & 0.45 & & & & & & 0.68 & 0.41 \\
\hline Randomized controlled trial & 13 & 0.38 & 0.19 & 0.01 & 0.75 & & & 13 & 0.42 & 0.16 & 0.10 & 0.74 & & \\
\hline Quasi-experimental study & 24 & 0.23 & 0.07 & 0.09 & 0.36 & & & 24 & 0.25 & 0.11 & 0.03 & 0.47 & & \\
\hline Study quality & & & & & & 0.57 & 0.75 & & & & & & 4.08 & 0.13 \\
\hline Medium (3-4) & 24 & 0.26 & 0.08 & 0.11 & 0.41 & & & 24 & 0.34 & 0.13 & 0.09 & 0.58 & & \\
\hline High (5-6) & 6 & 0.38 & 0.20 & 0.00 & 0.77 & & & 6 & 0.39 & 0.21 & -0.03 & 0.80 & & \\
\hline
\end{tabular}

Calculated using combined comparisons (Two arms, Control vs. AB, Control vs. ABC) with a total of 37 data sets. Moderator analysis was only done on moderators present in $>3$ studies.

\section{Funnel Plot of Standard Error by Hedges's $\mathbf{g}$}

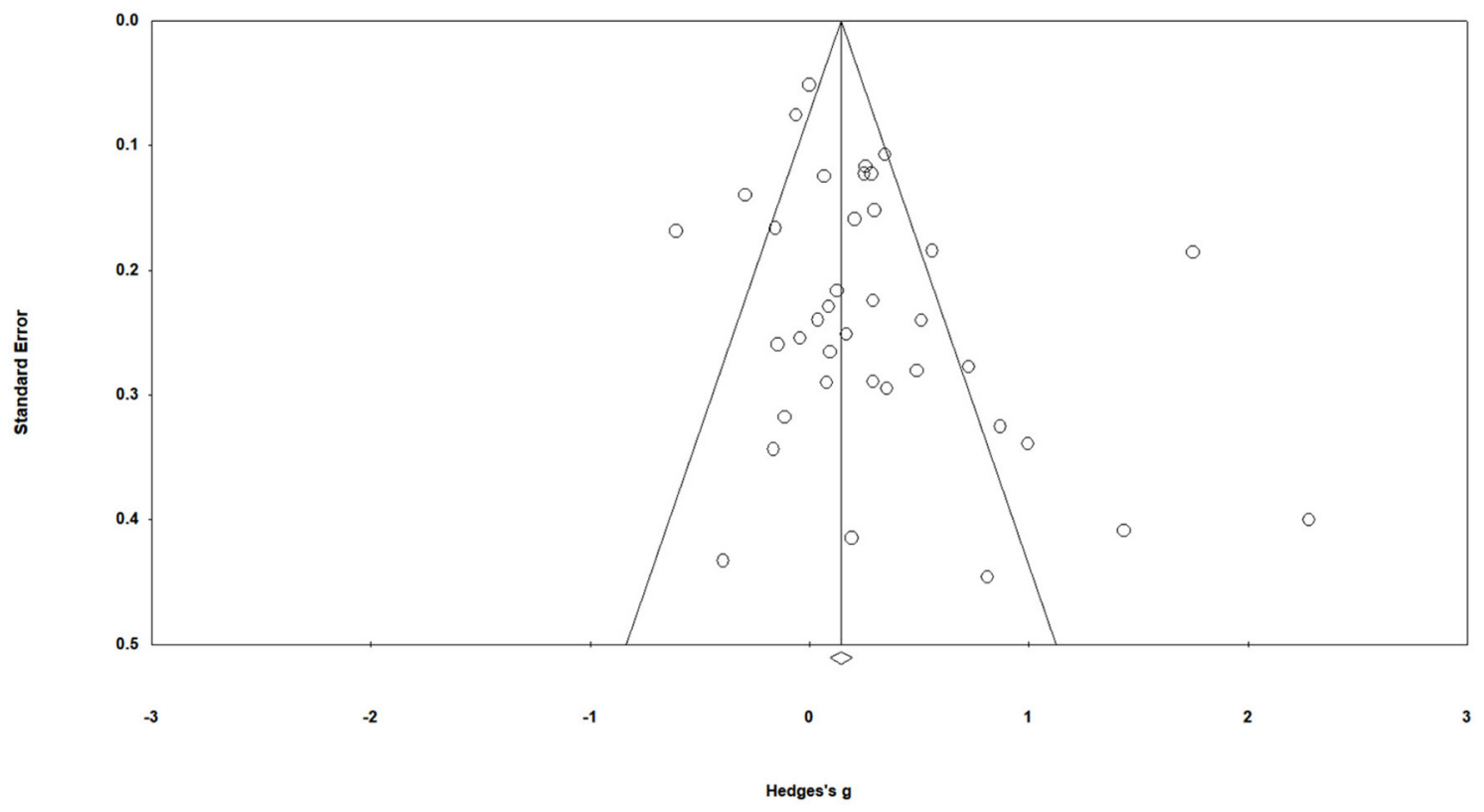

FIGURE 2 | Funnel plot of positive affective variables in this review.

Generally, PA consists of three elements: exercise intensity, exercise duration, and exercise frequency. However, only six of the 37 studies used accelerometers, and the others measured only one or two of the three elements of PA (subject's steps, heart rate, instrument usage, or possible time of exercise). Hence, in future studies, the accuracy of PA measurements could be improved further. Finally, eleven of 40 intervention techniques were utilized by $<3$ intervention groups, and their effectiveness should be explored better in relevant studies.

\section{Moderating Effect of Methodological and Demographic Variables on PAVs and PA}

The differences of effects between intervention and control conditions on both PAVs $(g=0.29 ; 95 \% \mathrm{CI}=0.15-0.43)$ and PA $(g=0.30 ; 95 \% \mathrm{CI}=0.11-0.49)$ were significant. Due to the studies' non-negligible heterogeneity, these considerable effect sizes should be interpreted with caution. Furthermore, our survey identified the underlying publication bias [Egger's intercept $t=1.65$ (35), $p=0.02$ ] in PAVs context. Given the significant publication bias in PAV, we further detected a larger effect size for small studies. Borenstein et al. (2009) noted that this pattern of larger effect size for small studies might because we retrieved a biased sample of small studies, but it is also possible that the effect size for small studies is larger for entirely unrelated reasons. That is, the presence of a smallstudy effect (Sterne et al., 2001) in PAVs may contribute to its publication bias. Under these circumstances, we recommend focusing on high-power studies and reducing studies with small samples to obtain more reliable estimates in future meta-analyses. Overall, no significant variations were found across the number 
Funnel Plot of Standard Error by Hedges's $\mathbf{g}$

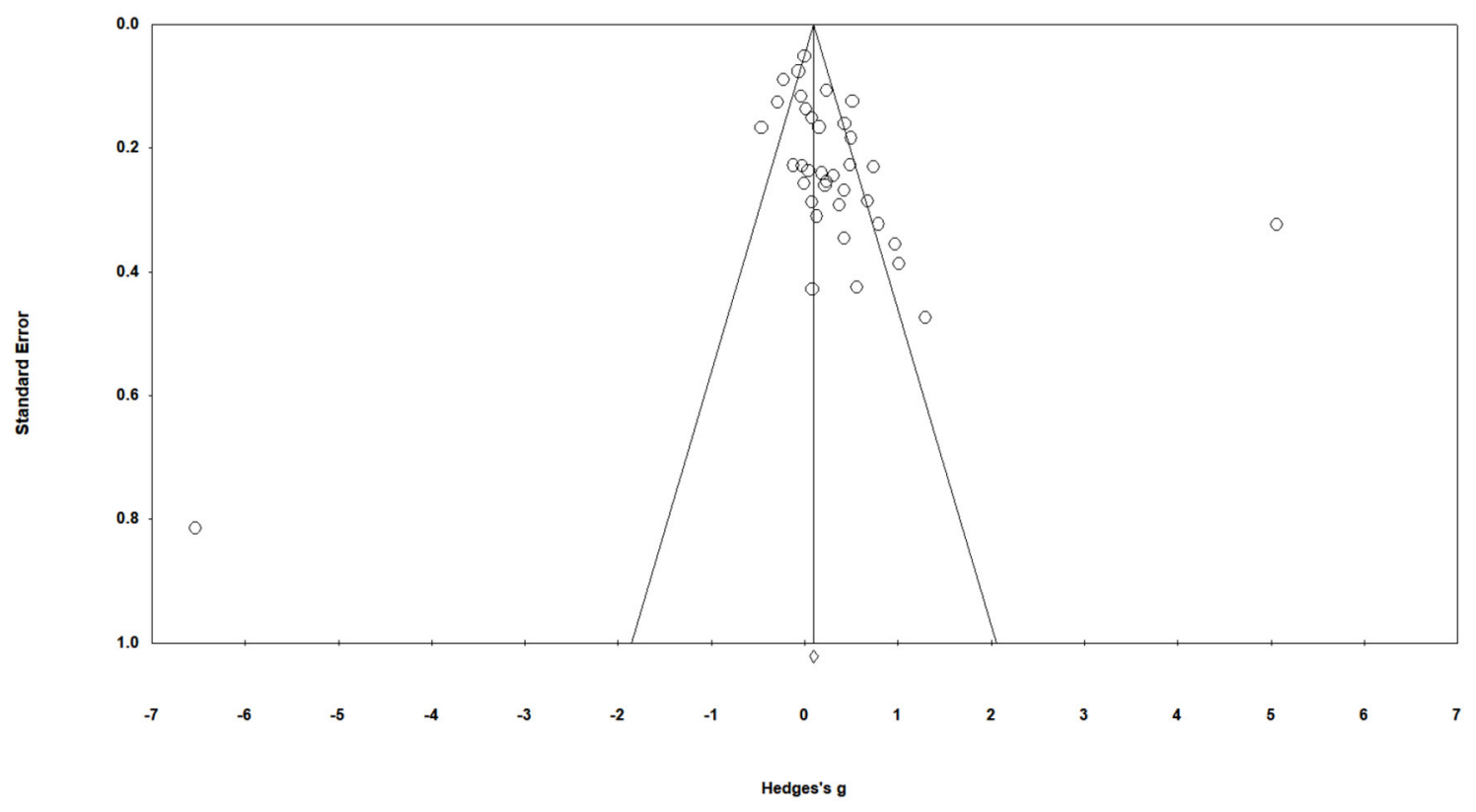

FIGURE 3 | Funnel plot of physical activity in this review.

of intervention methods used, PA at baseline, measurement employed, study design, or study quality assessment. However, age, gender, intervention duration, and theoretical framework significantly moderated the finding of PA. These findings were briefly discussed below.

a) Age moderated $P A V$ and $P A$. Studies at the age interval between 36 and 50 years reported the maximum effect size ( $g=0.48)$ in the PAV context, and subjects age between 18 and 35 reported the maximum effect size $(g=0.44)$ in the PA context. These results were consistent with those described by Lundqvist et al. (2013) and Vieillard and Gilet (2013): on the one hand, aging was associated with the maintenance of positive affect and the reduction of negative affect; on the other hand, a stimulus rating task showed that older adults had a considerably smaller range of responses to emotional stimuli than youngers. Besides, Kang et al. (2009) showed that separating interventions for different age groups was significantly more effective than not separating. Maybe one appropriate intervention strategy for one age group may not be appropriate for another age group. Therefore, we recommend selecting samples of approximately similar ages in a single study and administering higher intensity emotional stimulation to the young population in such interventions.

b) Gender moderated PA. Mixed samples $(g=0.30)$ reported larger changes than female samples $(g=0.07)$ in the PAV context, and mixed samples $(g=0.46)$ also reported larger changes than female samples $(g=-0.08)$ in the PA context. These findings are difficult to interpret because there are not enough male-only samples to compare to mixed samples. Future studies where participant gender is used as an ex post facto variable within the same design are needed to shed light on this finding.

c) Intervention duration moderated PAV. The results suggested that interventions shorter than 2 months showed the most significant effect size $(g=0.69)$. Based on this result, we take a long-term perspective and recommend that exercise intervention strategies should not be monotonous and constant over time but should be adjusted about once every 2 months in order to facilitate PAV growth.

d) Theory moderated PAV and PA. Interventions with SDT ( $g$ $=0.80$ ) had the most significant impact on PAV outcomes, while interventions without a theoretical basis $(g=1.03)$ had the most significant impact on PA. SDT posits that there are two main types of motivation-intrinsic and extrinsicand that both are powerful forces shaping who we are and how we act. When individuals are motivated by intrinsic motivation, they may feel self-directed and autonomous (Ryan and Deci, 2000). This result is understandable due to the numerous conceptual and content similarities between intrinsic motivation and PAVs (Wienke and Jekauc, 2016). Parallel to the aforementioned, the interventions without theory presented the most significant impact on PA, which may reveal the limited predictive power of current theoretical frameworks. These findings highlighted the importance of developing theory underpinnings of PA prediction and intervention. 
TABLE 4 | Comparison between PAVs and PA, according to whether a specific technique is present or absent in the intervention.

\begin{tabular}{|c|c|c|c|c|c|c|c|c|c|c|c|c|c|c|c|c|c|}
\hline \multicolumn{2}{|c|}{ Technique (moderator) } & \multicolumn{8}{|c|}{ PAVs } & \multicolumn{8}{|c|}{ PA } \\
\hline & & \multicolumn{3}{|c|}{ Present } & \multicolumn{3}{|c|}{ Absent } & \multirow[t]{2}{*}{$\mathbf{Q}$} & \multirow[t]{2}{*}{$p$} & \multicolumn{3}{|c|}{ Present } & \multicolumn{3}{|c|}{ Absent } & \multirow[t]{2}{*}{$\mathbf{Q}$} & \multirow[t]{2}{*}{$p$} \\
\hline & & $\boldsymbol{k}$ & $g$ & SE & $\boldsymbol{k}$ & $g$ & SE & & & $k$ & $g$ & SE & $k$ & $g$ & SE & & \\
\hline 1 & $\begin{array}{l}\text { Provide information on } \\
\text { consequences of behavior } \\
\text { in general }\end{array}$ & 15 & 0.29 & 0.11 & 34 & 0.32 & 0.08 & 0.05 & 0.83 & 15 & 0.54 & 0.13 & 34 & 0.26 & 0.09 & 3.45 & 0.04 \\
\hline 3 & $\begin{array}{l}\text { Provide information about } \\
\text { others' approval }\end{array}$ & 9 & 0.26 & 0.15 & 40 & 0.32 & 0.07 & 0.02 & 0.73 & 9 & 0.18 & 0.16 & 40 & 0.39 & 0.08 & 1.35 & 0.25 \\
\hline 4 & $\begin{array}{l}\text { Provide normative } \\
\text { information about others' } \\
\text { behavior }\end{array}$ & 5 & 0.43 & 0.23 & 44 & 0.30 & 0.07 & 0.28 & 0.60 & 5 & 0.40 & 0.26 & 44 & 0.35 & 0.08 & 0.05 & 0.83 \\
\hline 5 & Goal setting (behavior) & 19 & 0.29 & 0.10 & 30 & 0.33 & 0.08 & 0.12 & 0.73 & 19 & 0.39 & 0.11 & 30 & 0.32 & 0.10 & 0.25 & 0.61 \\
\hline 6 & Goal setting (outcome) & 6 & 0.24 & 0.19 & 43 & 0.32 & 0.07 & 0.15 & 0.70 & 6 & 0.39 & 0.22 & 43 & 0.35 & 0.08 & 0.04 & 0.84 \\
\hline 7 & Action planning & 28 & 0.20 & 0.08 & 21 & 0.38 & 0.10 & 2.21 & 0.14 & 28 & 0.33 & 0.09 & 21 & 0.38 & 0.12 & 0.10 & 0.75 \\
\hline 8 & $\begin{array}{l}\text { Barrier } \\
\text { identification/problem } \\
\text { solving }\end{array}$ & 18 & 0.09 & 0.10 & 31 & 0.45 & 0.08 & 7.79 & 0.01 & 18 & 0.19 & 0.11 & 31 & 0.46 & 0.09 & 3.43 & $<0.05$ \\
\hline 9 & Set graded tasks & 10 & 0.16 & 0.13 & 39 & 0.36 & 0.07 & 1.87 & 0.17 & 10 & 0.35 & 0.15 & 39 & 0.35 & 0.08 & 0.00 & 0.98 \\
\hline 10 & $\begin{array}{l}\text { Prompt review of behavioral } \\
\text { goals }\end{array}$ & 13 & 0.34 & 0.12 & 36 & 0.30 & 0.07 & 0.08 & 0.78 & 13 & 0.65 & 0.14 & 36 & 0.25 & 0.08 & 5.67 & 0.06 \\
\hline 11 & $\begin{array}{l}\text { Prompt review of outcome } \\
\text { goals }\end{array}$ & 3 & 0.43 & 0.23 & 46 & 0.30 & 0.07 & 0.28 & 0.60 & 3 & 0.40 & 0.26 & 46 & 0.35 & 0.08 & 0.05 & 0.83 \\
\hline 16 & $\begin{array}{l}\text { Prompt self-monitoring of } \\
\text { behavior }\end{array}$ & 24 & 0.24 & 0.09 & 25 & 0.37 & 0.09 & 1.12 & 0.29 & 24 & 0.28 & 0.11 & 25 & 0.42 & 0.10 & 0.88 & 0.35 \\
\hline 17 & $\begin{array}{l}\text { Prompt self-monitoring of } \\
\text { behavioral outcome }\end{array}$ & 4 & 0.15 & 0.20 & 45 & 0.33 & 0.07 & 0.75 & 0.39 & 4 & 0.36 & 0.24 & 45 & 0.35 & 0.08 & 0.00 & 0.96 \\
\hline 19 & $\begin{array}{l}\text { Provide feedback on } \\
\text { performance }\end{array}$ & 20 & 0.23 & 0.10 & 29 & 0.37 & 0.08 & 1.08 & 0.30 & 20 & 0.27 & 0.11 & 29 & 0.41 & 0.09 & 0.86 & 0.35 \\
\hline 20 & $\begin{array}{l}\text { Provide instruction on when } \\
\text { and where to perform the } \\
\text { behavior }\end{array}$ & 40 & 0.31 & 0.07 & 9 & 0.31 & 0.16 & 0.03 & 0.99 & 40 & 0.34 & 0.08 & 9 & 0.42 & 0.18 & 0.15 & 0.70 \\
\hline 21 & $\begin{array}{l}\text { Provide instruction on how } \\
\text { to perform the behavior }\end{array}$ & 41 & 0.32 & 0.07 & 8 & 0.27 & 0.18 & 0.06 & 0.80 & 41 & 0.36 & 0.08 & 8 & 0.32 & 0.21 & 0.04 & 0.84 \\
\hline 22 & $\begin{array}{l}\text { Model/demonstrate the } \\
\text { behavior }\end{array}$ & 28 & 0.28 & 0.08 & 21 & 0.36 & 0.10 & 0.29 & 0.60 & 28 & 0.43 & 0.09 & 21 & 0.23 & 0.12 & 1.75 & 0.19 \\
\hline 23 & Teach to use prompts/cues & 6 & 0.73 & 0.20 & 43 & 0.26 & 0.06 & 5.09 & 0.02 & 6 & 1.33 & 0.23 & 43 & 0.25 & 0.07 & 19.80 & $<0.01$ \\
\hline 24 & Environmental restructuring & 15 & 0.29 & 0.11 & 34 & 0.32 & 0.08 & 0.04 & 0.85 & 15 & 0.21 & 0.12 & 34 & 0.42 & 0.09 & 1.94 & 0.16 \\
\hline 26 & Prompt practice & 7 & 0.26 & 0.16 & 42 & 0.32 & 0.07 & 0.13 & 0.72 & 7 & 0.18 & 0.19 & 42 & 0.38 & 0.08 & 1.02 & 0.31 \\
\hline 27 & Use of follow-up prompts & 3 & 0.19 & 0.29 & 46 & 0.32 & 0.06 & 0.19 & 0.66 & 3 & 0.46 & 0.32 & 46 & 0.34 & 0.07 & 0.12 & 0.73 \\
\hline 28 & Facilitate social comparison & 4 & 0.98 & 0.25 & 45 & 0.26 & 0.06 & 7.95 & 0.01 & 4 & 0.97 & 0.28 & 45 & 0.30 & 0.07 & 5.45 & 0.02 \\
\hline 29 & $\begin{array}{l}\text { Plan social support/social } \\
\text { change }\end{array}$ & 25 & 0.19 & 0.08 & 24 & 0.45 & 0.09 & 4.11 & 0.04 & 25 & 0.41 & 0.10 & 24 & 0.28 & 0.11 & 0.86 & 0.35 \\
\hline 33 & Prompt self-talk & 4 & 0.04 & 0.23 & 45 & 0.33 & 0.07 & 1.53 & 0.22 & 4 & 0.22 & 0.26 & 45 & 0.36 & 0.08 & 0.26 & 0.61 \\
\hline 34 & Prompt use of imagery & 9 & 0.35 & 0.17 & 40 & 0.31 & 0.07 & 0.05 & 0.82 & 9 & 0.10 & 0.18 & 40 & 0.40 & 0.08 & 2.27 & 0.13 \\
\hline 35 & $\begin{array}{l}\text { Relapse prevention/coping } \\
\text { planning }\end{array}$ & 3 & 0.23 & 0.23 & 46 & 0.32 & 0.07 & 0.12 & 0.73 & 3 & 0.52 & 0.27 & 46 & 0.33 & 0.07 & 0.47 & 0.49 \\
\hline 36 & $\begin{array}{l}\text { Stress } \\
\text { management/emotional } \\
\text { training }\end{array}$ & 24 & 0.26 & 0.09 & 25 & 0.36 & 0.09 & 0.66 & 0.42 & 24 & 0.32 & 0.10 & 25 & 0.39 & 0.10 & 0.23 & 0.63 \\
\hline 37 & Motivational interviewing & 6 & 0.10 & 0.19 & 43 & 0.34 & 0.07 & 1.38 & 0.24 & 6 & 0.33 & 0.22 & 43 & 0.36 & 0.08 & 0.02 & 0.90 \\
\hline 38 & Time management & 4 & -0.16 & 0.25 & 45 & 0.34 & 0.07 & 3.62 & 0.06 & 4 & 0.08 & 0.27 & 45 & 0.37 & 0.08 & 1.08 & 0.30 \\
\hline 39 & $\begin{array}{l}\text { General communication } \\
\text { skills training }\end{array}$ & 5 & 0.05 & 0.18 & 44 & 0.35 & 0.07 & 2.54 & 0.11 & 5 & 0.13 & 0.20 & 44 & 0.38 & 0.08 & 1.39 & 0.24 \\
\hline
\end{tabular}

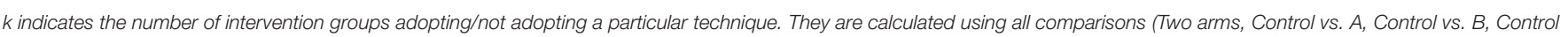
vs. C) with a total of 49 data sets. Moderator analysis was only done on moderators present in $>3$ intervention groups. 


\section{Moderating Effect of Contents Applied in the Intervention on PAVs and PA}

We found "teach to use prompts/cues" and "facilitate social comparison" were related to conceivable positive changes in PAV, and "teach to use prompts/cues," "facilitate social comparison," and "provides information on consequences of behavior in general" were related to positive changes in PA. These findings were briefly discussed below:

a) "Teach to use prompts/cues" positively moderated PAV and PA. The concept of "teach to use prompts/cues" is to instruct people to recognize environmental prompts (e.g., mobile phone reminders) that can be used to remind them to enact an intended behavior. This technique is desired as a planned, systematic delivery of cues to prompt people to do cognitive or metacognitive work on emotional arousal and PA to help people establish task-specific routines, automatic responses, or habits in their daily lives that internalize motivational factors and thus contribute to PA levels (Hayamizu, 1997). The TTM researchers note that teaching to use prompts/cues of PA behavior can facilitate individuals' transition from precontemplation stage to contemplation stage or even action stage. However, in explaining why this technique works, this theory only emphasizes consciousness-raising and ignoring PAVs' changes. Therefore, future TTM-based PA intervention studies could additionally consider the role of PAVs.

b) "Facilitate social comparison" moderated PAV and PA. It is not surprising that this technique enhanced both PAVs and $\mathrm{PA}$, as the technique in line with a critical construct of SDT. The SDT assigns a central role to intrinsic motivation, a construct that is typically operationalized by assessing the degree of enjoyment associated with behavioral preferences (Deci and Ryan, 2008). The concept of "facilitate social comparison" is to draw attention to the performance of others to elicit comparisons. According to SDT, individuals have three necessary psychological needs for intrinsic motivation to adopt and adhere to behaviors: the need for competence, the need for relatedness, and autonomy. We speculate that social comparisons enhance the subjects' sense of competition and the likelihood of perceiving their competence (Kwasnicka et al., 2016).

c) "Provide information on consequences of behavior in general" positively moderated PA. Its purpose is to provide information on the relationship between PA and its possible consequences in general cases, based on epidemiological data. One possible explanation for the positive effect is that the epidemiological data may have facilitated the valuation of PA as healthy, but this could also be a statistical fluke of the results of multiple comparisons, so further research on this topic is recommended.

In contrast, "barrier identification/problem solving" was negatively associated with PAVs and PA change, and "plan social support/social change" was related to an adverse change in PAVs. These findings were briefly discussed below:

a) "Barrier identification/ problem solving" negatively moderated PAV and PA. Both Koole and Rothermund (2011) and
Gyurak et al. (2011) pointed out the difference between explicit (requires conscious and cognitive effort to initiate and monitor) and implicit (operates without the need for conscious supervision) emotion regulation. Gyurak et al. (2011) also noted that although, by definition, implicit emotion regulation is not intentional (i.e., it is not instigated or guided by explicit intentions), some research emphasizes the goal-directed nature of implicit emotion regulation. This aspect of non-intentionality distinguishes the studies of implicit emotion regulation from most studies of explicit emotion regulation because implicit emotion regulation does not require such explicit instruction, so it is more spontaneous than explicit emotional regulation (Koole and Rothermund, 2011). Given that "barrier identification and problem solving" was defined as prompting the person to think about underlying obstacles and identifying methods to overcome them (Michie et al., 2011), we considered it to be a cognitive variable. In other words, we thought this cognitive variable to be an explicit rather than implicit process, which might have hindered PAVs and subsequent PA growth. In addition, as a common intervention technique based on SCT, we might have to consider its impact on environmental modification and also on affective variables. However, it was also possible that barrier identification was not necessarily ineffective, but instead that the technique was ineffective due to an incorrect implementation method.

b) "Plan social support/ social change" negatively moderated PAV. Although relatively little research has been done on the relationship between this variable and PAVs, the outcome is understandable. Because planning is an activity that requires the activation of an individual's cognitive resources, we consider this variable also to be an explicit rather than implicit process of emotion regulation. Based on the interaction between cognition and emotion (Liu et al., 2009), we speculate that complex cognition hinders the growth of PAVs. In general, social change is also a common intervention or environmental modification technique based on SCT. Future PA intervention studies using social support/social change need to address the impact on PAVs. However, this could also be a statistical fluke of multiple comparisons, and further research on this is recommended.

At present, new theoretical models of PA change have been developed based on the automatic affective valuation option, such as affective-reflective theory (ART; Brand and Ekkekakis, 2018) and the PA adoption and maintenance model (PAAM model; Strobach et al., 2020). However, they have not yet explored which specific BCTs would be helpful for enhancing positive affective evaluations (PAVs) in the healthy population, and this paper might be considered as a preliminary attempt.

\section{Limitations and Future Research Directions}

Although this review followed the Cochrane handbook for systematic reviews of interventions (Higgins et al., 2019b) as normatively as possible, several limitations still exist. First, the included studies were limited by search terms and language, and it was not possible to include all relevant studies. Future studies 
should consider including more languages to explore whether there are differences in manipulating positive affect variables and PA across countries or cultural contexts (e.g., Eastern and Western cultural contexts). Second, this study did not include unpublished data. However, given Bellefontaine and Lee (2014) explored the impact of including gray literature and found no significant differences in effect size and methodological quality with or without the inclusion of unpublished studies, we also considered this to be a minor limitation. Third, since it was not possible to split positive and negative affective variables into two, we only excluded negative affective variables. Fourth, due to data limitation, we could not analyze all 40 behavior change techniques listed in Michie et al. (2011), and only 29 BCTs were analyzed. Therefore, rigorous experimental testing using a factorial design that isolates and combines unique techniques is needed. Fifth, this paper focused on exploring the effectiveness of different BCTs, but not the effectiveness of affective change techniques, so more work needs to be done to gain insight into them. Sixth, given the broad age spectrum of the current study population, we expect future studies to narrow their age spectrum to explore age-specific intervention techniques. Seventh, the results might be inflated due to potential unit-of-analysis errors that might exist by using the current analytical methods. According to Cheung (2019) and Higgins et al. (2019a), multi-level meta-analysis and network metaanalysis are probably the best to deal with meta-analysis studies which include several effects from one study. Future studies should consider using them to achieve rigorous estimations.

\section{CONCLUSION}

Overall, the primary objective was to summarize the demographic, methodological, and BCTs of each study to review gaps in past experimental designs. Descriptive statistics showed that: at least 11 behavior change techniques were rarely used in included studies; the measurements of PAV dimensions and methods were highly inconsistent across studies; accelerometers were still not widely used in PA measurement. Inferential statistics yielded that: age, gender, intervention duration, and theoretical basis had significant moderating effects on PAV or PA outcomes; the utilization of "teach to use prompts/cues," "facilitate social comparison," and "provide information on consequences of behavior in

\section{REFERENCES}

Ajzen, I. (1991). The theory of planned behavior. Organ. Behav. Hum. Decis. Process. 50, 179-211. doi: 10.1016/0749-5978(91) 90020-T

Annesi, J. (2003). Effects of a cognitive behavioral treatment package on exercise attendance and drop out in fitness centers. Europ. J. Sport Sci. 3, 1-16. doi: 10.1080/17461390300073402

Ashford, S., Edmunds, J., and French, D. P. (2010). What is the best way to change self-efficacy to promote lifestyle and recreational physical activity? A systematic review with metaanalysis. Br. J. Health Psychol. 15, 265-288. doi: 10.1348/135910709X4 61752 general" had positive effects on PA or PAV outcomes; the utilization of "barrier identification/problem solving" and "plan social support/social change" negatively affected on PA or PAV outcomes. However, there was considerable heterogeneity in the findings, and the moderator analyses suggested that these effects may be exaggerated by publication and small sample bias. Nonetheless, this paper has considerable implications for future relative intervention studies, and these findings will serve as a base for future such intervention studies.

\section{DATA AVAILABILITY STATEMENT}

The original contributions presented in the study are included in the article/Supplementary Material, further inquiries can be directed to the corresponding author/s.

\section{AUTHOR CONTRIBUTIONS}

DJ and CC contributed to the study's conception and design. DJ supervised the entire process. CC organized the database, performed the statistical analysis, and wrote the manuscript. EF and AK supported $\mathrm{CC}$ in data extraction and data analysis phases. DJ, EF, and CC contributed to manuscript revision. All authors read and approved the submitted version.

\section{FUNDING}

This study was supported by the Chinese government scholarship-the Chinese Scholarship Council (CSC; No. 201608120055) scholarship. We also acknowledge support by the KIT-Publication Fund of the Karlsruhe Institute of Technology.

\section{ACKNOWLEDGMENTS}

We gratefully acknowledge the support of Peikai $\mathrm{Li}$ in the current investigation.

\section{SUPPLEMENTARY MATERIAL}

The Supplementary Material for this article can be found online at: https://www.frontiersin.org/articles/10.3389/fpsyg. 2021.628993/full\#supplementary-material

Bandura, A. (1998). Health promotion from the perspective of social cognitive theory. Psychol. Health 13, 623-649. doi: 10.1080/088704498084 07422

Bandura, A. (2004). Health promotion by social cognitive means. Health Educ. Behav. 31, 143-164. doi: 10.1177/1090198104263660

Batson, C. D., Shaw, L. L., and Oleson, K. C. (1992). "Differentiating affect, mood, and emotion: toward functionally based conceptual distinctions," in Emotion, ed. M. S. Clark (Newbury Park, CA: SAGE Publications), 294-326.

Bellefontaine, S. P., and Lee, C. M. (2014). Between black and white: Examining grey literature in meta-analyses of psychological research. J. Child Family Stud. 23, 1378-1388. doi: 10.1007/s10826-013-9795-1

Borenstein, M., Hedges, L., Higgins, J., and Rothstein, H. (2014). Comprehensive Meta Analysis V3. Englewood Cliffs, NJ: Biostat. 
Borenstein, M., Hedges, L. V., Higgins, J. P. T., and Rothstein, H. R. (2009). Introduction to Meta-Analysis. Chichester: John Wiley \& Sons. doi: 10.1002/9780470743386

Brand, R., and Ekkekakis, P. (2018). Affective-reflective theory of physical inactivity and exercise. Ger. J. Exerc. Sport Res. 48, 48-58. doi: 10.1007/s12662-017-0477-9

Breckler, S. J. (1984). Empirical validation of affect, behavior, and cognition as distinct components of attitude. J. Pers. Soc. Psychol. 47:1191. doi: 10.1037/0022-3514.47.6.1191

Bucks, R. S., and Radford, S. A. (2004). Emotion processing in Alzheimer's disease. Aging Ment. Health 8, 222-232. doi: 10.1080/13607860410001669750

Cacioppo, J. T., and Gardner, W. L. (1999). Emotion. Annu. Rev. Psychol. 50, 191-214. doi: 10.1146/annurev.psych.50.1.191

Carter, E. C., Schönbrodt, F. D., Gervais, W. M., and Hilgard, J. (2019). Correcting for bias in psychology: a comparison of meta-analytic methods. Adv. Methods Practic. Psychol. Sci. 2, 115-144. doi: 10.1177/2515245919847196

Caspersen, C. J., Powell, K. E., and Christenson, G. M. (1985). Physical activity, exercise, and physical fitness: definitions and distinctions for health-related research. Public Health Rep. 100, 126-131.

Chase, J.-A. D. (2015). Interventions to increase physical activity among older adults: a meta-analysis. Gerontologist 55, 706-718. doi: 10.1093/geront/gnu090

Chen, C., Finne, E., Kopp, A., and Jekauc, D. (2020). Can positive affective variables mediate intervention effects on physical activity? a systematic review and meta-analysis. Front. Psychol. 11:587757. doi: 10.3389/fpsyg.2020.587757

Cheung, M. W.-L. (2019). A guide to conducting a meta-analysis with non-independent effect sizes. Neuropsychol. Rev. 29, 1-10. doi: 10.1007/s11065-019-09415-6

Conn, V. S., Hafdahl, A. R., and Mehr, D. R. (2011). Interventions to increase physical activity among healthy adults: meta-analysis of outcomes. Am. J. Public Health 101, 751-758. doi: 10.2105/AJPH.2010.194381

Coyne, J. C., Thombs, B. D., and Hagedoorn, M. (2010). Ain't necessarily so: review and critique of recent meta-analyses of behavioral medicine interventions in health psychology. Health Psychol. 29:107. doi: 10.1037/a0017633

Davidson, R. (2003). Darwin and the neural bases of emotion and affective style. Ann. N. Y. Acad. Sci. 1000, 316-336. doi: 10.1196/annals.1280.014

Deci, E. L., Eghrari, H., Patrick, B. C., and Leone, D. R. (1994). Facilitating internalization: the self-determination theory perspective. J. Pers. 62, 119-142. doi: 10.1111/j.1467-6494.1994.tb00797.x

Deci, E. L., and Ryan, R. M. (2008). Self-determination theory: a macrotheory of human motivation, development, and health. Canad. Psychol. 49:182. doi: $10.1037 / \mathrm{a} 0012801$

Durlak, J. A. (2009). How to select, calculate, and interpret effect sizes. J. Pediatr. Psychol. 34, 917-928. doi: 10.1093/jpepsy/jsp004

Edwards, M. K., and Loprinzi, P. D. (2019). Affective responses to acute bouts of aerobic exercise, mindfulness meditation, and combinations of exercise and meditation: a randomized controlled intervention. Psychol. Rep. 122, 465-484. doi: $10.1177 / 0033294118755099$

Egloff, B. (1998). The independence of positive and negative affect depends on the affect measure. Pers. Individ. Dif. 25, 1101-1109. doi: 10.1016/S0191-8869(98)00105-6

Ekelund, U., Steene-Johannessen, J., Brown, W. J., Fagerland, M. W., Owen, N., Powell, K. E., et al. (2016). Does physical activity attenuate, or even eliminate, the detrimental association of sitting time with mortality? A harmonised metaanalysis of data from more than 1 million men and women. Lancet 388, 1302-1310. doi: 10.1016/S0140-6736(16)30370-1

Ekkekakis, P. (2017). People have feelings! Exercise psychology in paradigmatic transition. Curr. Opin. Psychol. 16, 84-88. doi: 10.1016/j.copsyc.2017.03.018

Ekkekakis, P., Hargreaves, E. A., and Parfitt, G. (2013). Invited Guest Editorial: envisioning the next fifty years of research on the exercise-affect relationship. Psychol. Sport Exer. 14, 751-758. doi: 10.1016/j.psychsport.2013.04.007

Ekkekakis, P., Hartman, M. E., and Ladwig, M. A. (2020). "Affective responses to exercise," in Handbook of Sport Psychology, eds G. Tenenbaum and R. C. Eklund (Toronto, ON: John Wiley \& Sons), 231-253. doi: 10.1002/9781119568124.ch12

Elm, E., von, Altman, D. G., Egger, M., Pocock, S. J., Gøtzsche, P. C., and Vandenbroucke, J. P. (2007). The Strengthening the Reporting of Observational Studies in Epidemiology (STROBE) statement: guidelines for reporting observational studies. Ann. Intern. Med. 147, 573-577. doi: 10.7326/0003-4819-147-8-200710160-00010
Finne, E., Englert, C., and Jekauc, D. (2019). On the importance of selfcontrol strength for regular physical activity. Psychol. Sport Exer. 43, 165-171. doi: 10.1016/j.psychsport.2019.02.007

*Fitzsimons, C. F., Baker, G., Gray, S. R., Nimmo, M. A., and Mutrie, N. (2012). Does physical activity counselling enhance the effects of a pedometer-based intervention over the long-term: 12-month findings from the Walking for Wellbeing in the west study. BMC Public Health 12, 1-12. doi: 10.1186/1471-2458-12-206

*Focht, B. C., Knapp, D. J., Gavin, T. P., Raedeke, T. D., and Hickner, R. C. (2007). Affective and self-efficacy responses to acute aerobic exercise in sedentary older and younger adults. J. Aging Phys. Act. 15, 123-138. doi: 10.1123/japa.15.2.123

Gellman, M. D., and Turner, J. R. (2013). Encyclopedia of Behavioral Medicine. New York, NY: Springer. doi: 10.1007/978-1-4419-1005-9

*Gråstén, A., and Yli-Piipari, S. (2019). The patterns of moderate to vigorous physical activity and physical education enjoyment through a 2-year schoolbased program. J. Schl. Health 89, 88-98. doi: 10.1111/josh.12717

Gyurak, A., Gross, J. J., and Etkin, A. (2011). Explicit and implicit emotion regulation: a dual-process framework. Cogn. Emot. 25, 400-412. doi: 10.1080/02699931.2010.544160

Hayamizu, T. (1997). Between intrinsic and extrinsic motivation: examination of reasons for academic study based on the theory of internalization. Japan. Psychol. Res. 39, 98-108. doi: 10.1111/1468-5884.00043

Hedges, L. V., and Pigott, T. D. (2004). The power of statistical tests for moderators in meta-analysis. Psychol. Methods 9:426. doi: 10.1037/1082-989X. 9.4.426

Higgins, J., and Li, T. (2019). "Chapter 6: Choosing effect measures and computing estimates of effect," in Cochrane Handbook for Systematic Reviews of Interventions Version 6.0 (updated July 2019), eds J. Higgins, T. Li, and J. Deeks (Cochrane), 587-588. doi: 10.1002/9781119536604.ch6

Higgins, J. P. T., Eldridge, S., and Li, T. (2019a). "Including variants on randomized trials," in Cochrane Handbook for Systematic Reviews of Interventions, eds J. P. T. Higgins, J. Thomas, J. Chandler, M. Cumpston, T. Li, M. J. Page, and V. A. Welch (Oxford: John Wiley \& Sons), 569-593. doi: 10.1002/9781119536604.ch23

Higgins, J. P. T., Thomas, J., Chandler, J., Cumpston, M., Li, T., Page, M. J., et al. (2019b). Cochrane Handbook for Systematic Reviews of Interventions. Chichester: John Wiley \& Sons. doi: 10.1002/9781119536604

Higgins, J. P. T., Thompson, S. G., Deeks, J. J., and Altman, D. G. (2003). Measuring inconsistency in meta-analyses. BMJ 327, 557-560. doi: $10.1136 /$ bmj.327.7414.557

Jekauc, D., and Brand, R. (2017). Editorial: how do emotions and feelings regulate physical activity? Front. Psychol. 8:1145. doi: 10.3389/fpsyg.2017.01145

Jekauc, D., Völkle, M., Wagner, M. O., Mess, F., Reiner, M., and Renner, B. (2015). Prediction of attendance at fitness center: a comparison between the theory of planned behavior, the social cognitive theory, and the physical activity maintenance theory. Front. Psychol. 6:121. doi: 10.3389/fpsyg.2015.00121

Kang, M., Marshall, S. J., Barreira, T. V., and Lee, J.-O. (2009). Effect of pedometerbased physical activity interventions: a meta-analysis. Res. Q. Exerc. Sport 80, 648-655. doi: 10.1080/02701367.2009.10599604

Kinnafick, F.-E., Thøgersen-Ntoumani, C., and Duda, J. (2016). The effect of need supportive text messages on motivation and physical activity behavior. J. Behav. Med. 39, 574-586. doi: 10.1007/s10865-016-9722-1

Koole, S. L., and Rothermund, K. (2011). "I feel better but I don't know why": the psychology of implicit emotion regulation. Cogn. Emot. 25, 389-399. doi: 10.1080/02699931.2010.550505

Kraemer, H. C., Gardner, C., Brooks III, J. O., and Yesavage, J. A. (1998). Advantages of excluding underpowered studies in meta-analysis: Inclusionist versus exclusionist viewpoints. Psychol. Methods 3:23. doi: 10.1037/1082-989X.3.1.23

*Kraft, J. A., Russell, W. D., Clark, N., Helm, J., and Jackson, A. (2015). Influence of experience level on physical activity during interactive video gaming. J. Phys. Activ. Health 12, 794-800. doi: 10.1123/jpah.2014-0089

Kwasnicka, D., Dombrowski, S. U., White, M., and Sniehotta, F. (2016). Theoretical explanations for maintenance of behavior change: a systematic review of behavior theories. Health Psychol. Rev. 10, 277-296. doi: 10.1080/17437199.2016.1151372

Larsen, J. T., Berntson, G. G., Poehlmann, K. M., Ito, T. A., and Cacioppo, J. T. (2008). "The psychophysiology of emotion," in Handbook of Emotions, 3rd 
Edn. eds. M. Lewis, J. M. Haviland-Jones, and L. F. Barrett (New York, NY: Guilford), 173-191.

Liu, Y., Fu, Q., and Fu, X. (2009). The interaction between cognition and emotion. Chin. Sci. Bull. 54:4102. doi: 10.1007/s11434-009-0632-2

Lundqvist, D., Svärd, J., and Fischer, H. (2013). Age-related differences in sensitivity to emotional facial stimuli but age-independent association between arousal ratings and visual search efficiency. Psihologijske teme 22, 271-286.

McEwan, D., Harden, S. M., Zumbo, B. D., Sylvester, B. D., Kaulius, M., Ruissen, G. R., et al. (2016). The effectiveness of multi-component goal setting interventions for changing physical activity behavior: a systematic review and meta-analysis. Health Psychol. Rev. 10, 67-88. doi: $10.1080 / 17437199.2015 .1104258$

Michie, S., Ashford, S., Sniehotta, F. F., Dombrowski, S. U., Bishop, A., and French, D. P. (2011). A refined taxonomy of behavior change techniques to help people change their physical activity and healthy eating behaviors: the CALO-RE taxonomy. Psychol. Health 26, 1479-1498. doi: 10.1080/08870446.2010.540664

*Miragall, M., Domínguez-Rodríguez, A., Navarro, J., Cebolla, A., and Baños, R. M. (2018). Increasing physical activity through an internet-based motivational intervention supported by pedometers in a sample of sedentary students: a randomized controlled trial. Psychol. Health 33, 465-482. doi: $10.1080 / 08870446.2017 .1368511$

Moher, D., Liberati, A., Tetzlaff, J., and Altman, D. G. (2009). Preferred reporting items for systematic reviews and meta-analyses: the PRISMA statement. PLoS Med. 6:e1000097. doi: 10.1371/journal.pmed.1000097

Moustaka, F. C., Vlachopoulos, S. P., Kabitsis, C., and Theodorakis, Y. (2012). Effects of an autonomy-supportive exercise instructing style on exercise motivation, psychological well-being, and exercise attendance in middle-age women. J. Phys. Activ. Health 9, 138-150. doi: 10.1123/jpah.9.1.138

*Niedermeier, M., Einwanger, J., Hartl, A., and Kopp, M. (2017). Affective responses in mountain hiking-a randomized crossover trial focusing on differences between indoor and outdoor activity. PLoS ONE 12:e0177719. doi: 10.1371/journal.pone.0177719

Nielsen, G., Wikman, J. M., Jensen, C. J., Schmidt, J. F., Gliemann, L., and Andersen, T. R. (2014). Health promotion: the impact of beliefs of health benefits, social relations and enjoyment on exercise continuation. Scand. J. Med. Sci. Sports 24(Suppl. 1), 66-75. doi: 10.1111/sms.12275

*Noradechanunt, C., Worsley, A., and Groeller, H. (2017). Thai Yoga improves physical function and well-being in older adults: a randomized controlled trial. J. Sci. Med. Sport 20, 494-501. doi: 10.1016/j.jsams.2016.10.007

Ostrom, T. M. (1969). The relationship between the affective, behavioral, and cognitive components of attitude. J. Exp. Soc. Psychol. 5, 12-30. doi: 10.1016/0022-1031(69)90003-1

Penedo, F. J., and Dahn, J. R. (2005). Exercise and well-being: a review of mental and physical health benefits associated with physical activity. Curr. Opin. Psychiatry 18, 189-193. doi: 10.1097/00001504-200503000-00013

Prochaska, J. O., and Velicer, W. F. (1997). The transtheoretical model of health behavior change. Am. J. Health Promot. 12, 38-48. doi: 10.4278/0890-1171-12.1.38

Reich, J. W., Zautra, A. J., and Potter, P. T. (2001). Cognitive structure and the independence of positive and negative affect. J. Soc. Clin. Psychol. 20, 99-115. doi: $10.1521 /$ jscp.20.1.99.22255

Rhodes, R. E., Fiala, B., and Conner, M. (2009a). A review and meta-analysis of affective judgments and physical activity in adult populations. Ann. Behav. Med. 38, 180-204. doi: 10.1007/s12160-009-9147-y

Rhodes, R. E., Gray, S. M., and Husband, C. (2019). Experimental manipulation of affective judgments about physical activity: a systematic review and meta-analysis of adults. Health Psychol. Rev. 13, 18-34. doi: 10.1080/17437199.2018.1530067

Rhodes, R. E., and Kates, A. (2015). Can the affective response to exercise predict future motives and physical activity behavior? A systematic review of published evidence. Ann. Behav. Med. 49, 715-731. doi: 10.1007/s12160-015-9704-5

*Rhodes, R. E., Warburton, D. E. R., and Bredin, S. S. D. (2009b). Predicting the effect of interactive video bikes on exercise adherence: an efficacy trial. Psychol. Health Med. 14, 631-640. doi: 10.1080/135485009032 81088

*Rose, E. A., and Parfitt, G. (2007). A quantitative analysis and qualitative explanation of the individual differences in affective responses to prescribed and self-selected exercise intensities. J. Sport Exer. Psychol. 29, 281-309. doi: 10.1123 /jsep.29.3.281

Ryan, R. M., and Deci, E. L. (2000). Self-determination theory and the facilitation of intrinsic motivation, social development, and well-being. Am. Psychol. 55, 68-78. doi: 10.1037/0003-066X.55.1.68

*Schneider, M., and Cooper, D. M. (2011). Enjoyment of exercise moderates the impact of a school-based physical activity intervention. Int. J. Behav. Nutr. Phys. Act 8, 1-8. doi: 10.1186/1479-5868-8-64

Shah, K. N., Majeed, Z., Yoruk, Y. B., Yang, H., Hilton, T. N., McMahon, J. M., et al. (2016). Enhancing physical function in HIV-infected older adults: a randomized controlled clinical trial. Health Psychol. 35, 563-573. doi: $10.1037 /$ hea0000311

Shiota, M. N., and Kalat, J. W. (2012). Emotion. Belmont, CA: Wadsworth, Cengage Learning.

Shouse, E. (2005). Feeling, emotion, affect. M/c J. Media Cult. 8:2443. doi: $10.5204 / \mathrm{mcj} .2443$

Silva, M. N., Markland, D., Vieira, P. N., Coutinho, S. R., Carraça, E. V., Palmeira, A. L., et al. (2010a). Helping overweight women become more active: need support and motivational regulations for different forms of physical activity. Psychol. Sport Exer. 11, 591-601. doi: 10.1016/j.psychsport.2010.06.011

Silva, M. N., Vieira, P. N., Coutinho, S. R., Minderico, C. S., Matos, M. G., Sardinha, L. B., et al. (2010b). Using self-determination theory to promote physical activity and weight control: a randomized controlled trial in women. J. Behav. Med. 33, 110-122. doi: 10.1007/s10865-009-9239-y

Sterne, J. A. C., Egger, M., and Smith, G. D. (2001). Investigating and dealing with publication and other biases in meta-analysis. BMJ 323, 101-105. doi: $10.1136 /$ bmj.323.7304.101

Strobach, T., Englert, C., Jekauc, D., and Pfeffer, I. (2020). Predicting adoption and maintenance of physical activity in the context of dual-process theories. Perform. Enhance. Health 8:100162. doi: 10.1016/j.peh.2020.100162

van Cappellen, P., Rice, E. L., Catalino, L. I., and Fredrickson, B. L. (2018). Positive affective processes underlie positive health behavior change. Psychol. Health 33 , 77-97. doi: 10.1080/08870446.2017.1320798

Vanhees, L., Lefevre, J., Philippaerts, R., Martens, M., Huygens, W., Troosters, T., et al. (2005). How to assess physical activity? How to assess physical fitness? Europ. J. Cardiovasc. Prevent. Rehabil. 12, 102-114. doi: 10.1097/00149831-200504000-00004

Vieillard, S., and Gilet, A.-L. (2013). Age-related differences in affective responses to and memory for emotions conveyed by music: a cross-sectional study. Front. Psychol. 4:711. doi: 10.3389/fpsyg.2013.00711

*Wang, J. C. K., Leng, H. K., and Kee, Y. H. (2015). Use of Facebook in physical activity intervention programme: test of self-determination theory. Int. J. Sport Psychol. 46, 210-224.

Watson, D., Wiese, D., Vaidya, J., and Tellegen, A. (1999). The two general activation systems of affect: Structural findings, evolutionary considerations, and psychobiological evidence. J. Pers. Soc. Psychol. 76, 820-838. doi: 10.1037/0022-3514.76.5.820

Weinberg, R. S., and Gould, D. (2014). Foundations of Sport and Exercise Psychology. Champaign, IL: Human Kinetics.

Wienke, B., and Jekauc, D. (2016). A qualitative analysis of emotional facilitators in exercise. Front. Psychol. 7:1296. doi: 10.3389/fpsyg.2016.01296

Williams, S. L., and French, D. P. (2011). What are the most effective intervention techniques for changing physical activity self-efficacy and physical activity behavior-and are they the same? Health Educ. Res. 26, 308-322. doi: $10.1093 /$ her/cyr005

Conflict of Interest: The authors declare that the research was conducted in the absence of any commercial or financial relationships that could be construed as a potential conflict of interest.

Copyright $\odot 2021$ Chen, Finne, Kopp and Jekauc. This is an open-access article distributed under the terms of the Creative Commons Attribution License (CC BY). The use, distribution or reproduction in other forums is permitted, provided the original author(s) and the copyright owner(s) are credited and that the original publication in this journal is cited, in accordance with accepted academic practice. No use, distribution or reproduction is permitted which does not comply with these terms. 